\title{
Marsectohexol and other pregnane phytochemicals derived from Gongronema latifolium as $a$-amylase and $a$-glucosidase inhibitors: in vitro and molecular docking studies
}

\author{
O. M. Ogunyemi ${ }^{1,4}$ (D) A. G. Gyebi ${ }^{1} \cdot$ J. O. Adebayo ${ }^{2} \cdot$ J. A. Oguntola ${ }^{3} \cdot$ C. O. Olaiya ${ }^{4}$
}

Received: 21 July 2020 / Accepted: 24 November 2020 / Published online: 1 December 2020

(c) Springer Nature Switzerland AG 2020

\begin{abstract}
This study employed in vitro and in silico techniques to screen isolated pregnane phytochemicals (P1-P4), as well as their source pregnane-rich chromatographic fractions, which were derived from Gongronema latifolium Benth (GLB), for their inhibitory potentials against $a$-amylase, $a$-glucosidase, and sucrase enzyme activities. The results show that, most pregnane-rich chromatographic fractions and isolated compounds exhibited good inhibitory activities against $a$-amylase, and $a$-glucosidase enzymes. Among the isolated compounds, marsectohexol (P2) is the most favourable structure that showed inhibition against $a$-amylase $\left(\mathrm{IC}_{50}=3.712 \mu \mathrm{g} / \mathrm{mL}\right)$ when compared with the reference inhibitor, acarbose ( $\left(I C_{50}=15.418 \mu \mathrm{g} / \mathrm{mL}\right)$. Based on negative and low value of $\Delta \mathrm{G}$ (Gibb's free energy), docking scores revealed that, marsectohexol has the highest binding affinity $(-8.8 \mathrm{kcal} / \mathrm{mol})$ to human pancreatic $a$-amylase (HPA) as compared to the standard acarbose $(-8.1 \mathrm{kcal} / \mathrm{mol})$. Marsectohexol and the other phytocompounds were also found to dock into the active site of HPA; interacting with key catalytic amino acid residues (ASP197, GLU233 and ASP300), which are known to involve in the nucleophilic, and the acid/base catalysis of the enzyme. Although, the pregnane phytocompounds have considerable high affinity binding to the human lysosomal $a$-glucosidase, they interacted with pockets other than the active site. In conclusion, at least, marsectohexol and three other constituent pregnane phytochemicals of GLB are potential inhibitors of the carbohydrate-hydrolyzing enzymes. These compounds may account for the anti-hyperglyceamic and antidiabetic potentials of this food herb.
\end{abstract}

Keywords Pregnanes · Pregnane glycosides $\cdot$ Nutraceuticals $\cdot$ Gongronema latifolium $\cdot$ Diabetes $\cdot$ In silico

\section{Introduction}

Metabolic disorders such as hyperglycaemia, diabetes mellitus (DM), obesity, and hypertension are major health problems among world's population [1-3]. Important carbohydrate-hydrolysing enzymes such as a-amylase, and a-glucosidase enzymes play key roles in the breakdown of starch, oligosaccharides and disaccharides into monosaccharides for absorption [4,5]; and thereby serve as key targets for phytomedicines towards suppressing carbohydrate digestion, and delaying glucose uptake in the gut [6]. In practice, several synthetic drugs such as acarbose, voglibose, and miglitol are potent inhibitors of carbohydrate- hydrolysing enzymes; however, these drugs are associated with undesirable effects such as bloating, abdominal discomfort, diarrhea, and flatulence

O. M. Ogunyemi, omogunyemi1@gmail.com | ${ }^{1}$ Human Nutraceuticals and Bioinformatics Research Unit, Department of Biochemistry, Salem University, PMB 1060, Lokoja, Kogi State, Nigeria. ${ }^{2}$ Department of Biochemistry, Faculty of Life Sciences, University of Ilorin, Ilorin, Nigeria. ${ }^{3}$ Biochemistry Unit, Department of Biological Sciences, Faculty of Pure and Applied Sciences, Southwestern University, ljebu-Ode, Nigeria. ${ }^{4}$ Nutritional and Industrial Biochemistry Research Unit, Department of Biochemistry, College of Medicine, University of Ibadan, Ibadan 200005, Nigeria. 
[7]. Utilizing natural antidiabetic agents, which can constrain carbohydrate metabolizing enzymes in human gut, is a promising oral policy for blunting postprandial plasma glucose rise; and alleviating diabetes, obesity, and other metabolic syndromes $[8,9]$.

Gongronema latifolium Benths (GLB) is a green leafy vegetable and food herb widespread in Nigeria and tropical and subtropical regions of Africa, as well as some parts of Asia, [10-12]. This dietary component is highly valued for its health utility; being associated with various biological activities such as anti-oxidant, anti-inflammation, antiulcer, anti-hypertension, anti-malarial, and anti-microbial activities [10,13-15]. GLB has been used as antidiabetic spice and vegetable in traditional folk medicine in the southern parts of Nigeria and other parts of Africa [10]. Besides, the leaves are incorporated into a tea blend that is mainly marketed to diabetes mellitus patients in the United States [16, 17]. Several in vivo studies have helped to provide support for the ethnopharmacological use of GLB against hyperglycaemia, obesity, and diabetes [18-20]. For instance, methanol extracts alone and in combination with glibenclamide decreased the blood glucose from 1 to $6 \mathrm{~h}$ post-treatment in alloxan-induced hyperglycaemic rats [21]. Also, treatments of rats with ethanolic and aqueous leaf extracts of GLB caused a dose- and timedependent decrease in the blood glucose level compared to control [22]. While several in vivo studies have revealed the anti-hyperglycaemic potential of GLB [23-25], the underlying mechanism is not fully understood.

Towards the phytochemical and biological characterization of GLB which may further support its nutritional and ethnopharmacological use in humans, several classes of phytochemicals such as: pregnanes, phytosterols, anthraquinones, and essential oils have been identified [20, 26-28]. Such phytochemicals, which are characterized by large-scale structures, are known to possess high efficiency and ability to bind to multifarious targets [29-31]. The current study employed in vitro and in silico techniques for screening isolated pregnanes phytochemicals alongside their source pregnane-rich extracts and chromatographic fractions derived from GLB for $a$-amylase, $a$-glucosidase, and sucrase enzyme inhibitory activities.

\section{Materials and methods}

\subsection{Plant materials, extraction and purification of compounds}

The leaf samples of Gongronema latifolium were earlier extracted in $80 \%$ methanol and fractionated to yield several solvent fractions. The ethylacetate partition fraction was subjected to several chromatographic and spectrometric (1D-NMR, 2D-NMR, infrared and Mass spectrometry) techniques to yield 5 phytocompounds of which 4 were pregnanes and its glycosides. The isolation procedure and elucidation of the structures have been reported in our previous study. [27]. In the current study, selected solvent partition fraction (n-hexane, ethyl acetate and methanol), pregnane-rich chromatographic fraction (Fr. 2-10), and pregnane phytochemicals, namely: lloneoside (P1), marsectohexol (P2), 3-0-[6-deoxy-3-Omethyl- $\beta$-D-allopyranosyl-( $1 \rightarrow 4)-\beta$-Doleandropyranosyl]$17 \beta$-marsdenin (P3) and 3-0-[6-deoxy-3-O-methyl$\beta$-D-allopyranosyl-( $1 \rightarrow 4)-\beta$-D-canaropyranosyl]$17 \beta$-marsdenin (P4) were screened for $\alpha$-amylase, $a$-glucosidase, and sucrase enzyme inhibitory activities.

\subsection{Inhibition assay for a-amylase activity}

In vitro inhibitory activity of the partition fractions, chromatographic fractions and isolated pregnane and pregnane glycosides against $a$-amylase were assessed using the same protocol as described in the literature [32] with slight modification. Acarbose was used as standard. The percent of inhibition was determined by the formular:

Inhibition percentage $=\frac{B-S}{B} \times 100$

$\mathrm{B}$ and $\mathrm{S}$ are the absorbances for the blank and samples respectively.

\subsection{Inhibition assay for a-Glucosidase activity}

a-Glucosidase activity was determined according to the method described by Kim, Jeong [33] with slight modification. Briefly, 5 units of $a$-glucosidase were pre-incubated with different concentrations of the samples for $15 \mathrm{~min}$. Para-nitrophenylglucopyranoside (PNPG) (3 mM) dissolved in $20 \mathrm{mM}$ phosphate buffer, $\mathrm{pH} 6.9$ was added to start the reaction. The reaction mixture was further incubated at $37^{\circ} \mathrm{C}$ for $20 \mathrm{~min}$ and stopped by addition of $2 \mathrm{ml}$ of $0.1 \mathrm{M}$ $\mathrm{Na}_{2} \mathrm{CO}_{3}$. The $a$-glucosidase activity was determined by measuring the yellow colored p-nitrophenol released from PNPG at $400 \mathrm{~nm}$. The assay measurements in \% inhibition as well as the $\mathrm{IC}_{50}$ calculations were performed using the same procedure as in a-amylase enzyme assay.

\subsection{Inhibition assay for sucrase activity}

Sucrase activity was assayed according to the method of Honda and Hara [34] with slight modification. The enzyme solution $(10 \mu \mathrm{l})$ and varying concentrations of the samples were incubated together for $10 \mathrm{~min}$ at $37^{\circ} \mathrm{C}$, and the volume was made up to $200 \mu \mathrm{L}$ with maleate buffer $(\mathrm{pH}$ 
6.0). The enzyme reaction was started by adding $100 \mu \mathrm{l}$ sucrose solution $(60 \mathrm{mM})$. After $30 \mathrm{~min}$, the reaction was terminated by adding $200 \mu \mathrm{L}$ of 3,5-dinitrosalysilic acid reagent and treating the mixture in a boiling water bath for five minutes. The absorbance of the solution was read at $540 \mathrm{~nm}$. The assay measurements in \% inhibition as well as the $I C_{50}$ calculations were performed using the same procedure as in $\alpha$-amylase enzyme assay.

\subsection{Molecular docking analysis}

Interactions between the phytochemicals, human pancreatic a-amylase (HPA) and human lysosomal acid- $a$ glucosidase (HLG) were studied by in silico molecular docking in order to explore the preferred orientation of the ligands in the receptors binding site. The crystal structures of the proteins for the docking studies were retrieved from the Protein Data Bank (http://www.rcsb.org) with identification codes: HPA (PDB code:1b2y) and HLG (PDB code: $5 \mathrm{NN} 8$ ). The structure of acarbose was retrieved from the PubChem database (www.pubchem.ncbi.nlm.nih.gov), while the pregnanes and its glycosides were drawn with Chemdraw version 19. All the water molecules and the cocrystallized ligand were removed from the structures as demonstrated earlier [35]. The compounds were docked to the active regions of the target enzymes using Autodock vina in PyRx0.8 [36]. The result of the top most docked compound obtained from vina was further validated by BINDSURF (https://bio-hpc.ucam.edu/achilles/) [37]. The saved pdb format of the proteins was uploaded into PyRx 0.8. Compound structures in pdb format were imported and energy minimization was performed via OpenBabel software. All the other parameters were kept as default. The molecular interactions between proteins and selected compounds with higher binding affinity to the proteins were viewed with Discovery Studio Visualizer version 16.

\subsection{Statistical analysis}

Analysis was performed using Microsoft Excel, 2010, Graphpad Software and SAS 9.12. One-way analysis of variance (ANOVA) and Duncan Multiple Range were used to evaluate the possible differences among the means. The data were expressed as the mean \pm SEM and $p<0.05$ were considered as significant differences.

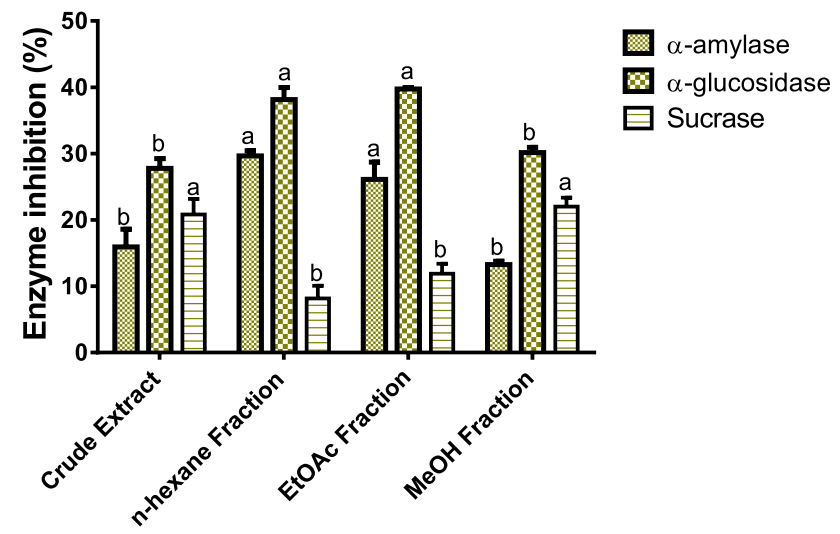

Fig. 1 Inhibitory effects of G. latifolium crude extract and solvent fractions against digestive enzymes at $200 \mu \mathrm{g} / \mathrm{mL}$. The means with different letters in the same figure were significantly different based on Duncan's multiple range. Test at $a=0.05$

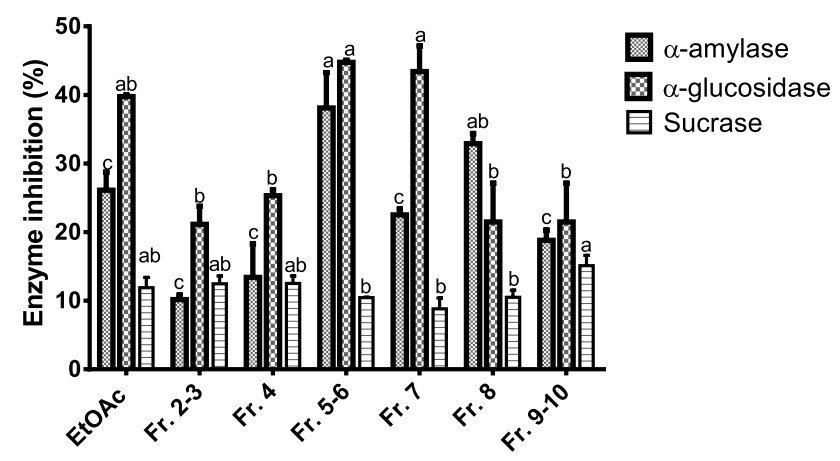

Fig. $2 a$-amylase, and $a$-glucosidase and sucrase enzymes inhibitory activities of the ethyl acetate fraction and its chromatographic sub fractions at $100 \mu \mathrm{g} / \mathrm{mL}$. The means with different letters in the same figure were significantly different based on Duncan's multiple range. Test at $a=0.05$

\section{Results}

\subsection{In vitro a-amylase, a-glucosidase and sucrase inhibitory effect}

Results in Fig. 1 show the enzyme inhibitory activity of the crude extract and solvent partition fraction from GLB.

While the order of $a$-glucosidase inhibition for the different fractions was ethyl acetate $(39.75 \%)>n$-hexane $(38.13 \%)>$ methanol $(30.16 \%)>$ crude $(27.77 \%)$; that of amylase was $n$-hexane $(29.64 \%)>$ ethyl acetate $(27.11 \%)>$ crude $(15.94 \%)>$ methanol $(13.27 \%)$. Overall, ethyl acetate fractions show the strongest inhibition against target enzymes as compared to other fractions.

The results of the screening of column chromatography-derived pregnane- fractions (10 sub-fractions) from the ethyl acetate fractions are represented in Fig. 2. 
While the order of a-Glucosidase inhibition was: Fr. $5 / 6>$ Fr.7 $>$ ethyl acetate $>$ Fr. $4>$ Fr. 8; the order of amylase inhibition was Fr. 5/6 $>$ Fr.8 $>$ ethyl acetate $>$ Fr.7 $>$ Fr. $9 / 10$. Most chromatographic fractions show more inhibition against glucosidase and amylase than sucrase.

The inhibitory activities of the isolated pregnane compounds from the chromatographic fractions of GLB (Fig. 3) are shown in Fig. 4.

The summarized results in Fig. $4 a-c$ show that, most pregnane compounds displayed a concentration dependent inhibitory effects against the target enzymes. Figure $4 \mathrm{~d}$ shows the inhibitory effect against $a$-amylase $\left(3.71<\mathrm{IC}_{50}<31.15 \mu \mathrm{g} / \mathrm{mL}\right)$, $a$-glucosidase $\left(31.12<\mathrm{IC}_{50}<71.08 \mu \mathrm{g} / \mathrm{mL}\right)$ and sucrase $\left(47.86<\mathrm{IC}_{50}<52.34 \mu \mathrm{g} / \mathrm{mL}\right)$. The highest inhibitory activity was ascribed to compound $\mathrm{P} 2$ against $\mathrm{a}$ - amylase with $\mathrm{IC}_{50} 3.712 \mu \mathrm{g} / \mathrm{mL}$ when compared with the other compounds and the reference acarbose ((acarbose, $I_{50}=15.418 \mu \mathrm{g} / \mathrm{mL}$ ). Furthermore, most compounds exhibited stronger inhibitory potential against a- amylase and a- glucosidase as targets than sucrase.

\subsection{Molecular docking of pregnane phytochemicals against $\boldsymbol{\alpha}$-amylase and $\mathbf{a}$-glucosidase}

The binding energies $\Delta G$ (Gibbs energy) represented by the AutoDock Vina docking scores of the compounds and acarbose with the target enzymes are shown in Table 1.

The result revealed that, acarbose, the reference inhibitors, had binding affinity $-8.1 \mathrm{kcal} / \mathrm{mol}$ for the active region of $a$-amylase. Using acarbose, and ranking based on negative and low value of $\Delta G$, marsectohexol is the top most docking compound with $-8.8 \mathrm{kcal} / \mathrm{mol}$, which is followed by P4 $(-8.0 \mathrm{kcal} / \mathrm{mol})$.

Visualization of the HPA active region, which was defined by a grid box size of $18.90 \times 10.24 \times 54.04 \AA$ centered at $(x, y, z)$ of $(20.59,19.94,21.58) \AA$, and containing the catalytic residues (ASP197, GLU233, and ASP300), in complex with the ligands revealed that, acarbose was docked into the active site of a-amylase (Fig. 5).

Acarbose-HPA complex was characterized by conventional hydrogen bond with the active site ASP197 and HIS305; Carbon Hydrogen interactions with ASP197 and TYR151; and a m-Alkyl interaction with HIS305 (Table 1; Fig. 5). All the pregnane phytochemicals were well docked to the active site region; mimicking the binding and interactions of the reference inhibitor: acarbose (Fig. 5).

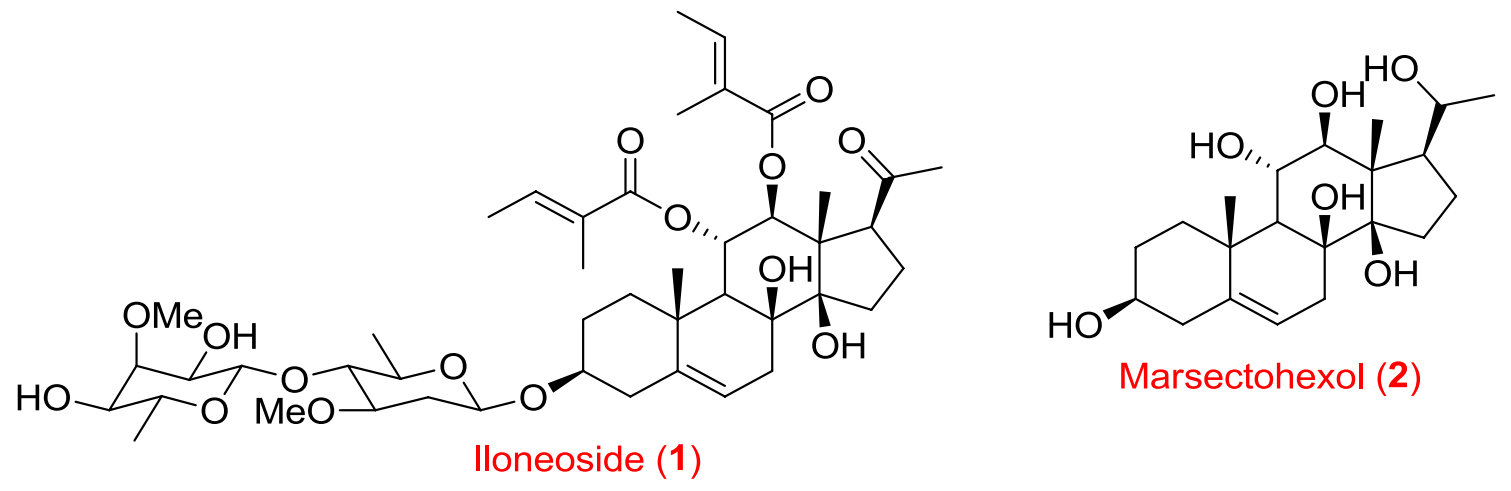

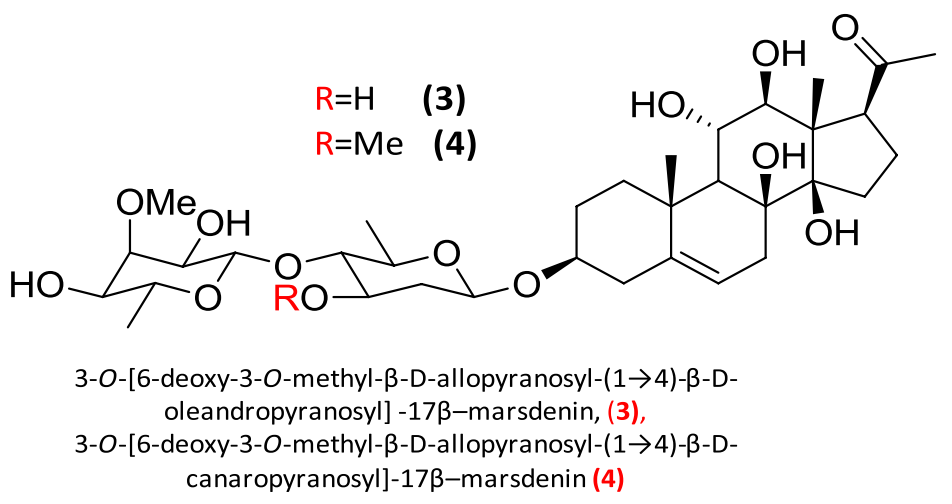

Fig. 3 Chemical structures of the pregnane and pregnane glycosides isolated from G. Iatifolium 

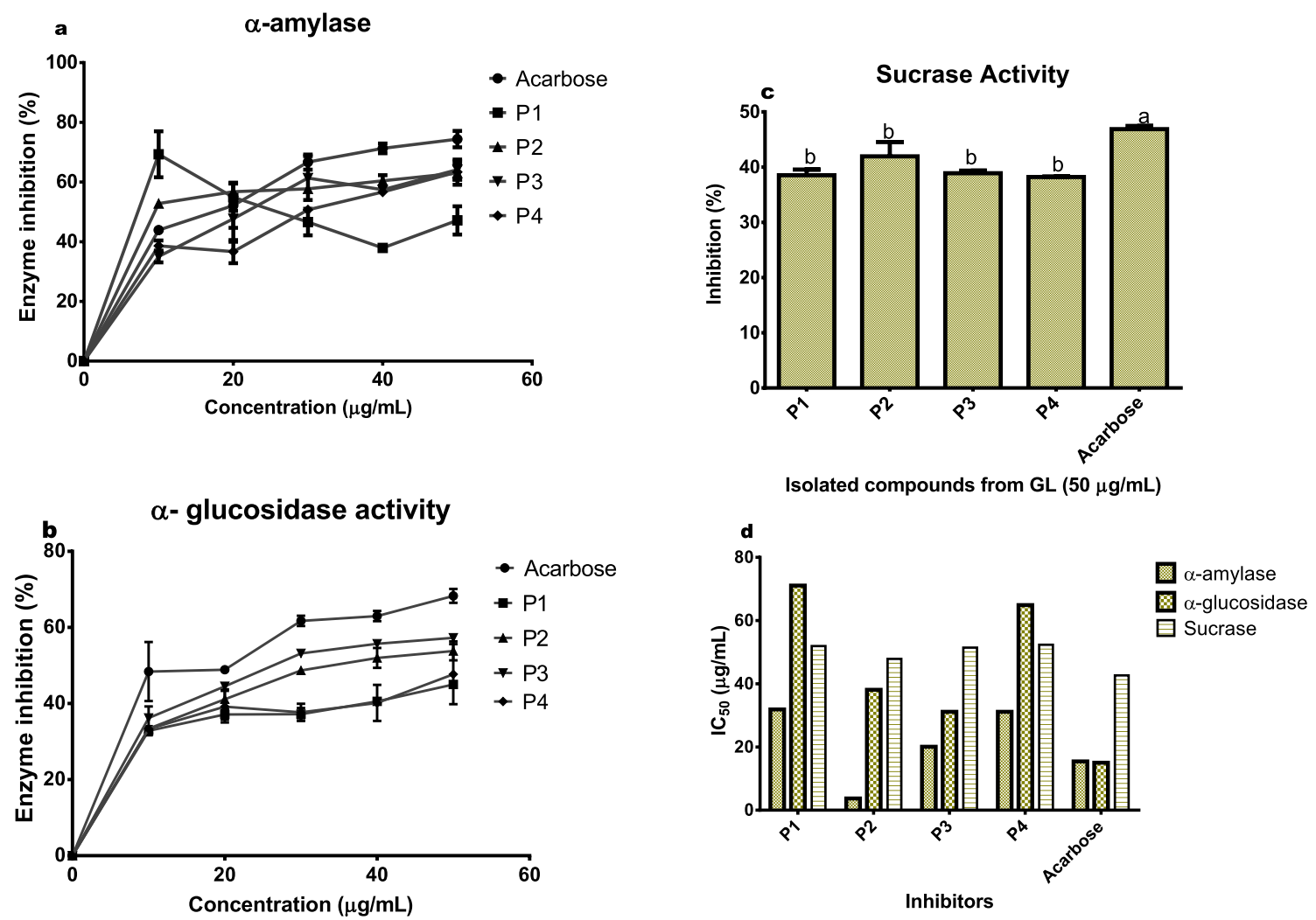

Fig. 4 Inhibitory effects of isolated compounds and standard inhibitor on: a $a$-amylase activity b a-glucosidase activity c sucrase activity and $\mathbf{d} I \mathrm{IC}_{50}$ of the compounds for the target enzymes

Table 1 Binding affinities and amino acid interactions of compounds with enzyme

\begin{tabular}{|c|c|c|c|c|}
\hline Compounds & Enzymes & $\begin{array}{l}\text { Binding } \\
\text { energy (Kcal/ } \\
\text { mol) }\end{array}$ & Hydrogen bonds (Bond distance) & Other interactions \\
\hline Acarbose & $\mathrm{HPA}$ & -8.1 & $\mathrm{HIS}^{305}(2.79) \operatorname{ASP}^{197}(2.55)$ & ASP $^{197}$ TYR $^{151}$ HIS $^{305}$ \\
\hline $\mathrm{P} 1$ & & -5.0 & $\begin{array}{l}\operatorname{Thr}^{163}(1.67) \operatorname{LYS}^{200}(2.68,2.44) \operatorname{HIS}^{305}(2.61,2.05) \\
\operatorname{GLY}^{306}(2.64) \operatorname{ASP}^{300}(2.31) \operatorname{GLU}^{233}(3.72)\end{array}$ & ALA $^{198}$ ALA $^{307}$ ILE $^{235}$ LUE $^{237}$ TRP $^{58}$ TRP $^{59}$ TYR $^{62}$ \\
\hline $\mathrm{P} 2$ & & -8.8 & $\operatorname{GLY}^{306}(2.43) \operatorname{ASP}^{300}(2.29,2.38) \operatorname{GLU}^{233}(2.80)$ & LEU $^{162}$ ALA $^{198}$ LEU $^{165}$ TRP $^{58}$ TYR $^{62}$ \\
\hline P3 & & -6.8 & $\operatorname{HIS}^{299}(1.91) \mathrm{GLU}^{240}(2.48) \mathrm{GLY}^{306}(2.37)$ & TYR $^{62}$ TYR $^{151}$ LYS $^{200}$ HIS $^{101}$ HIS $^{305}$ \\
\hline P4 & & -8.0 & $\operatorname{LYS}^{200}(2.76,2.62) \mathrm{HIS}^{305}(2.67)$ & GLU $^{233}$ LEU $^{162}$ ALA $^{198}$ ILE $^{235}$ TRP $^{58}$ TRP $^{59}$ \\
\hline Acarbose & HLG & -7.2 & $\operatorname{ARG}^{281}(2.56,2.16,1.85) \operatorname{ALA}^{555}(1.97) \operatorname{ASP}^{282}(2.38,2.15)$ & ASP 616 \\
\hline $\mathrm{P} 1$ & & -6.9 & None & LEU $^{678}$ TRP $^{376}$ TRP $^{481}$ PHE $^{525}$ \\
\hline $\mathrm{P} 2$ & & -6.3 & None & LEU $^{678}$ LEU $^{677}$ TRP $^{376}$ TRP $^{481}$ \\
\hline P3 & & -7.8 & $\operatorname{ASP}^{282}(1.99)$ & $\mathrm{ALA}^{555} \mathrm{LEU}^{678} \mathrm{TRP}^{376} \mathrm{TRP}^{481} \mathrm{PHE}^{525}$ \\
\hline P4 & & -7.5 & $\operatorname{ARG}^{281}(2.24) \mathrm{PHE}^{525}(2.63)$ & PHE $^{525}$ LEU $^{677}$ LEU $^{678}$ TRP $^{378}$ TRP $^{481}$ \\
\hline
\end{tabular}

Marsectohexol, the topmost docked compound to HPA, was found to utilize multiple interactions with the binding and catalytic residues of the enzyme. It interacted via hydrogen bonds with GLU233, ASP300, and GLY306; Alkyl hydrophobic interactions with LEU162, ALA198, LEU165; and $\pi$-alkyl hydrophobic interactions with TRP58 and TYR62 (Table 1 and Fig. 5). The pregnane glycosides
(P1, P3, and P4) were also well docked to the active site region of HPA like acarbose and $P 2$ but with less binding affinity. The pregnane glucoside- HPA complexes involve multiple interactions such as hydrogen bonds, and hydrophobic interactions, depending on the amino acid composition of binding sites and chemical properties of the compounds (Table 1 and Fig. 5). A considerable 


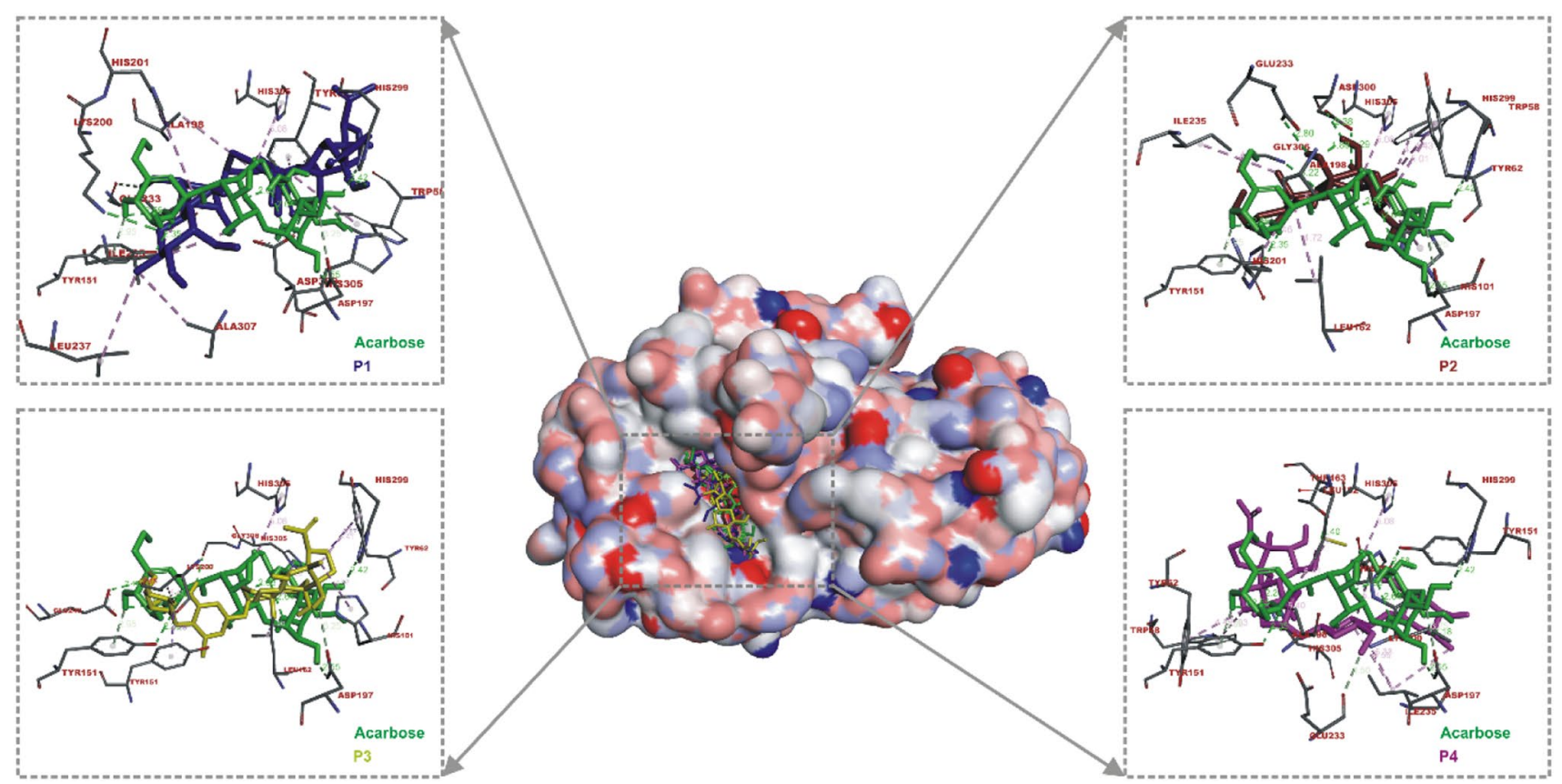

Fig. 5 Surface view of pregnane compounds (P1-P4) and acarbose in binding cavity of Human Pancreatic amylase (HPA)

strong interaction found between P1 and the active site of a-amylase involve: conventional hydrogen bonds with ASP300, GLY306, HIS305, LYS200, and THR163; carbon hydrogen bond with GLU233; alkyl hydrophobic interactions with ALA198, ALA307, ILE235, and LEU237; $\pi$-alkyl hydrophobic interactions with TRP58, TRP59, and TYR62 (Table 1, and Fig. 5).
In the case of a-glucosidase, P3 $(-7.8 \mathrm{Kcal} / \mathrm{mol})$ and P4 $(-7.5 \mathrm{Kcal} / \mathrm{mol})$ which are the topmost docked compounds had higher binding affinity for the enzyme active site than that of acarbose (-7.2Kcal/mol) (Table 1 and Fig. 6).

Acarbose was docked into the active site of this enzyme by interacting with the catalytic residue ASP616 through carbon- hydrogen interaction (Fig. 6). Unlike the

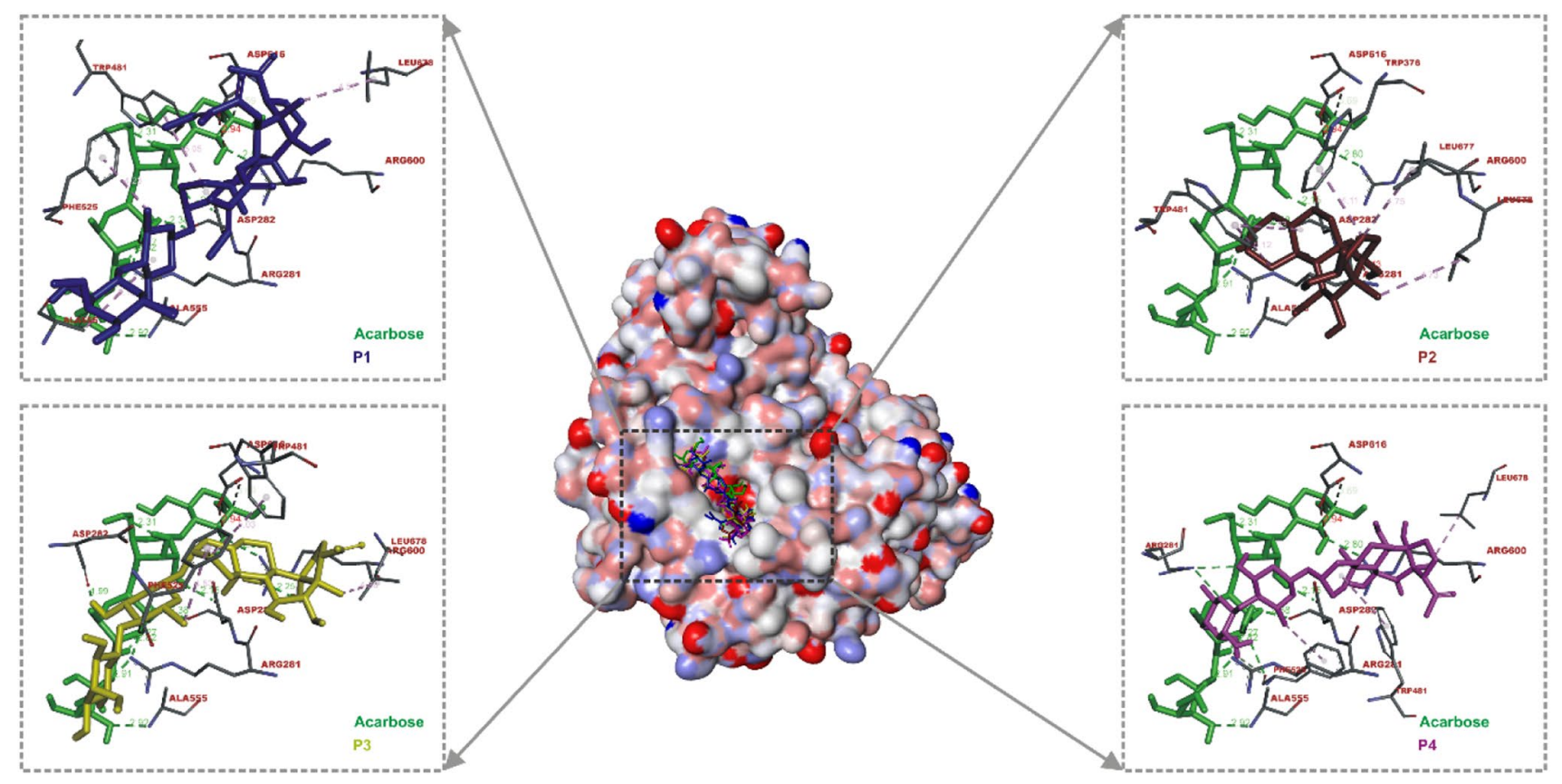

Fig. 6 Surface view of pregnane compounds (P1-P4) and acarbose in binding cavity of Human Lysosoma Glucosidase (HLG) 
ligand-HPA complex, the compounds had limited interactions with the binding and catalytic residues of HLG; thus, were not able to mimic the binding of acarbose in the enzyme active site (Fig. 6). Among the interactions detected, hydrogen bonds and hydrophobic interactions played prominent roles; and involve amino acid residues such as ASP282, PHE525, ARG281, LEU677 (Table 1).

\subsection{Revalidation and energy profile analyses of marsectohexol docking to target enzymes}

BINDSURF analysis was used to perform exhaustive series of docking calculations across the whole protein surface to validate and assess the energy profile of the P2-enzyme complexes. The binding energies and the poses with the best binding affinities as revealed by BINDSURF are presented in Table 2.

Marsectohexol was docked into the same active site cavity on a-amylase with a close binding affinity $(-8.30 \mathrm{kcal} / \mathrm{mol})$ as revealed by AutoDock Vina. BINDSURF revealed additional active site residues in the P2-HPA complex such as hydrogen bond interaction with ASP197, HIS305, and GLN63. In the case of HLG, marsectohexol was found to be docked into a cavity on the a-glucosidase other than the active site with high affinity $(-7.3 \mathrm{kcal} /$ $\mathrm{mol}$ ) than AutoDock Vina scores. In this binding pocket as defined by $(-1.44,-10.33,82.08)$, marsectohexol interacted with TYR360, HIS584, ARG594, HIS717, and GLU866 via hydrogen bond. It also interacted with MET363 and LEU865 via hydrophobic interactions (Table 2).

Figure 7 shows the energetic contributions to binding energy of marsectohexol to the target enzymes.

The greatest impact for the interactions of marsectohexol with HPA and HLG were contributed by electrostatic energies described as Gauss 1 and Gauss 2. While P2-HPA complex was characterized by a higher energy of hydrophobic interactions than of hydrogen bonds (Fig. 7a), P2-HLG complex exhibited significantly higher hydrogen bond compared to hydrophobic interactions (Fig. 7b). Hydrogen bonds occurred mainly at the oxygen atom $\mathrm{O} 40$ and $\mathrm{O} 60$ of P2 in the active site of HPA, but their formation caused a repulsive effect, weakening the overall effect of energetic affinity (Fig. 7a). Compound P2 employed extra

Table 2 Highest BINDSURF score and binding spot of marsectohexol on target enzymes

\begin{tabular}{lllll}
\hline Complex & Binding energy & $\begin{array}{l}\text { Poses } \\
\text { in clus- } \\
\text { ter }\end{array}$ & $\begin{array}{c}\text { Best pose } \\
\text { Binding site coor- } \\
\text { dinate }\end{array}$ \\
\hline P2-HPA & -8.30 & 96 & 194 & $(20.29,6.47,47.42)$ \\
P2-HLG & -7.30 & 91 & 618 & $\begin{array}{c}(-1.44),-10.33, \\
82.08)\end{array}$ \\
\hline
\end{tabular}

oxygen atom $\mathrm{O} 38$, in addition to $\mathrm{O} 40$ and $\mathrm{O} 60$ for the formation of hydrogen bonds with HLG. The energetic effect associated with the rotation also contributed to the weakening of the interactions, but for the two target enzymes investigated it was of marginal significance.

\section{Discussion}

Elucidation of the bioactive components in Gongronema latifolium (Benth) may contributes to its ongoing phytochemical and biological characterization; and promote its dietary use in Nigeria and other parts of Africa. Owing to the extensive ethnopharmacological use of this food herb and its widely reported anti-hyperglyceamic actions, it is considered as a unique vegetal resource agents that may modulate metabolic syndrome such as hyperglyceamia, diabetes, and obesity [38-40]. Bioprospecting such bioactive agents from GLB may be achieved more rapidly by employing in vitro and in silico techniques which are characterized by search space minimization and resources maximization. In this study, we demonstrated the inhibitory actions of four pregnane phytochemicals alongside their source chromatographic fractions derived from GLB against a-amylase, a-glucosidase and sucrase in vitro. The observed inhibitory potential of the pregnane- rich chromatographic fractions derived from GLB provides mechanistic insights into the in vivo anti-hyperglycaemic and anti-diabetic activities of various extracts from GLB extensively reported for over a decade [18-20, 28].

Recently, pregnane phytochemicals have been suggested and explored as potential anti-diabetic and antiobesity agents $[24,41]$. This study revealed that, pregnane and pregnane glycosides derived from GLB showed inhibitory potential against amylase and glucosidase in vitro. This study supports several in vivo reports on the antihyperglyceamic activity and anti-obesity actions of pregnane compounds from plant sources. For instance, Russelioside B, a pregnane glycoside obtained from Caralluma quadrangula was shown to ameliorate hyperglycemia in diabetic streptozotocin induced diabetic rats by regulating key enzymes of glucose metabolism [23]. This compound also showed anti-obesity action on high fat diet fed rats due to its favorable effect on energy expenditure [24]. In addition, a recent study revealed that, five novel pregnane glycosides, derived from the ethanol extract of the stem of Gymnema sylvestre, and named gymsylosides A-E exhibited $a$-amylase and $a$-glucosidase inhibitory activities [42].

Marsectohexol, a pregnane with $\mathrm{IC}_{50}=3.712 \mu \mathrm{g} / \mathrm{mL}$ showed the most remarkable inhibitory potential against a-amylase as compared to other compounds (the glycoside derivatives). This compound contains the C-21 steriodal framework present in other pregnane glycoside (P1, 
Fig. 7 Energetic contributions to binding energy of Marsectohexol (P2) and: a Human Pancreatic a-amylase (HPA); b Human Lysosomal a-glucosidase (HLG); blue bar-Gauss 1 interactions; green-Gauss 2 interactions; red-Repulsion; light blueHydrophobic interaction; magenta-Hydrogen bonds; olive-Rotational; back-Total affinity
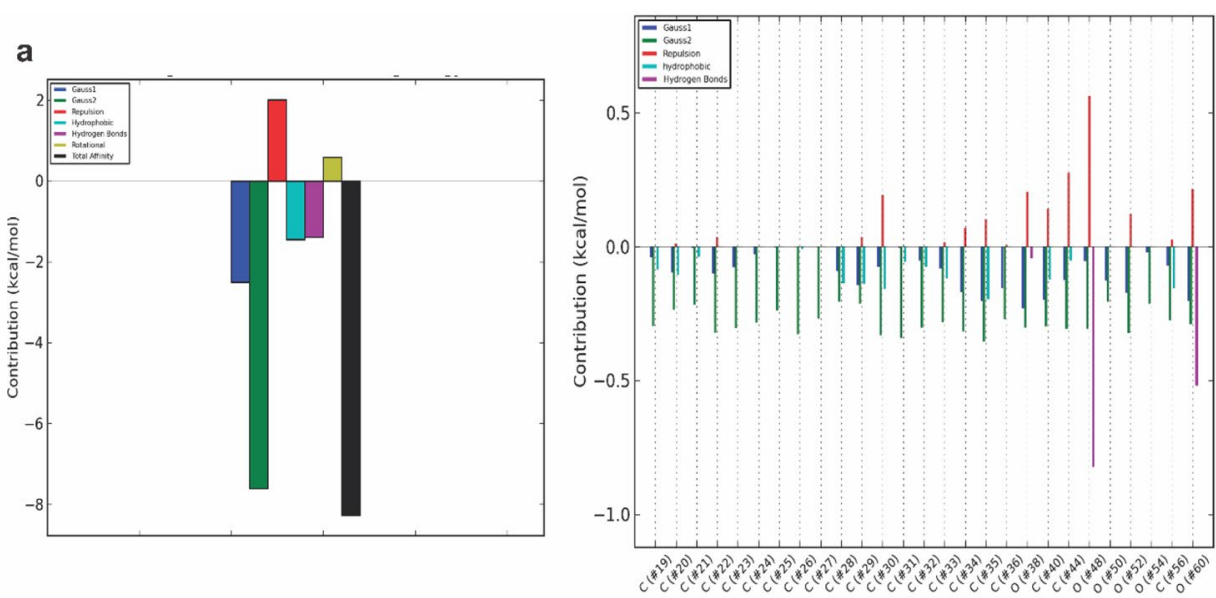

b

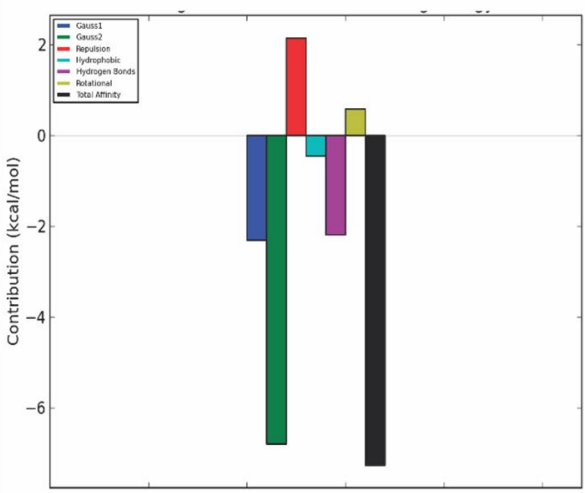

P2 and P4) but differs due to the absence of additional tigloyl substituent at $\mathrm{C}-11$ and $\mathrm{C}-12$ of $\mathrm{P} 1$ and sugar moiety attached to the alcoholic group at $\mathrm{C}-3$ of the aglycone moiety of the glycoside derivatives. This suggests that the glycosylation of the aglycon may have reducing impart on the a-amylase inhibitory activity of the pregnanes. With regards to a-glucosidase, $\mathrm{P} 2-4$ demonstrated better concentration dependent inhibition of a-glucosidase than P1. Replacing the hydroxyl group at $\mathrm{C}-11$ and $\mathrm{C}-12$ of $\mathrm{P} 1$ with the tigloyl substituent may have been responsible for the reduced activity. Similar reports to ours have demonstrated in vitro $a$-glucosidase inhibitory activity of eight pregnane-type steroidal glycosides (gymnema griffithosides $\mathrm{A}-\mathrm{H}$ ) isolated from the methanolic extract of the pericarp of Gymnema griffithii fruits [43].

In principle, binding of known inhibitors to specific sites on a-amylase and a-glucosidase molecules is generally known to involve several mechanisms which include: potency to construct hydrogen bonds with catalytic acid residues, ionic and hydrophobic interactions at sites other than the active site, ionic bonds with nucleophilic catalysing residues, or covalent bond with enzymes through an epoxy, or aziridine group [44, 45], Molecular docking analyses using AutoDock Vina, which utilizes its scoring function (Vina) to predict the interaction between ligand and target proteins, was used to assess the binding affinity of the ligand and the preferred orientation of the ligands in the active sites of the enzymes. The docking results revealed that, the pregnane structures bind to HPA active site. Providing the X-ray crystal structure and enzyme kinetics studies on a-amylase, it has been demonstrated that the active site of $a$-amylase contain three important residues namely ASP197, GLU233 and ASP300 [46-48]. Their mechanism of action on the hydrolysis of polymeric substrates such as starch was conducted as follows: ASP197 acts as a nucleophile, however GLU233 intervenes in acid-base catalysis during the hydrolysis reaction and ASP300 play a role in optimizing the orientation of the substrate. This study revealed that, marsectohexol and the other pregnane phytochemicals exhibit strong interactions with the binding and catalytic site residues in the amylase active site (Table 1 and Fig. 5); thus, are dubbed competitive inhibitors of this enzyme. A similar report by Williams, Li [48] revealed that, myricetin as a HPA inhibitor

\section{SN Applied Sciences}


can binds at the active site of a-amylase via four hydrogen bond interactions with GLN63, HIS101 and ASP197 and two hydrophobic interactions with TYR62 and LEU165, respectively. Also, several amino acid residues such as TRP59, VAL98, LEU162, VAL163, ALA198, and GLU233 can stabilize more the myricetin a-amylase complex. As shown in Fig. 5, our docking results are well correlated with this finding, suggesting that the pregnane phytochemicals were well bounded at the active site of the $a$ - amylase at a place close to the binding site of myricetin with also the presence of the important 3 residues (ASP197, GLU233 and ASP300) of the active site.

Although, acarbose was well docked to the active site region; interacting with important active site residues (ASP518 and ASP616), which mainly act as a catalytic nucleophile and acid/base respectively in the classical Koshland double displacement reaction mechanism [49]. The compounds tend to exhibit high affinity binding and interactions with other sites than the HLG active site as demonstrated by marsectohexol (Table 2). Therefore, an uncompetitive mode of inhibition is suggested as the compounds may bind to a regulatory site bind to several regions of the enzyme other than the active site. The advantage of such compounds over standard acarbose is that, they may not be affected by higher concentrations of the substrate; and inhibition may not be reversed by increase in substrate concentration.

\section{Conclusion}

The present work contributes to the ongoing phytochemical and biological characterization of the popular GLB widely used for nutritional and medicinal purposes in Nigeria and other parts of Africa. At least four component pregnane phytochemicals derived from GLB showed inhibitory potential against amylase and glucosidase in vitro and in silico. Marsectohexol is the most favourable pregnane structures that showed highest inhibition in vitro as well as most favourable interaction with a-amylase active site amino acid residues in silico. The marsectohexol-enzyme complexes are stabilized by hydrogen bond, hydrophobic interactions and electrostatic interactions. Since marsectohexol (P2), which is a pregnane, differ mainly in the attached sugar moieties to the $\mathrm{C}-3$ of the aglycon of the other Pregnane phytochemicals, (pregnane glycosides), the sugar moieties in P1, P3, and P4, may be associated with reduction in biological activities. At least, marsectohexol and the other pregnane compounds from GLB may account for its anti-hyperglyceamic activities; thus, may be recommended for further in vivo studies geared towards their exploiation in complementary and nutraceutical treatment of hyperglyceamia, diabetes and obesity.

Acknowledgements The authors are grateful to Prof. Mamoru Koketsu (Department of Chemistry and Biomolecular Science, Faculty of Engineering, Gifu University, Gifu, Japan), for availing his laboratory resources and Prof. Olufunke E. Olorundare for the initial chemical investigation of the plant. The technical support of Dr. Oso BJ of McPherson University, Nigeria is also acknowledged.

Funding This research did not receive any specific grant from funding agencies in the public, commercial, or not-for-profit sectors.

\section{Compliance with ethical standards}

Conflicts of interest The authors declare that they have no conflict of interests.

\section{References}

1. Olaiya CO, Choudhary MI, Ogunyemi OM, Nwauzoma AB (2013) Nutraceuticals from bitter leaf (Vernonia amygdalina Del.) protects against cadmium chloride induced hypertension in albino rats. Nat Sci 11(6):36-145

2. Chatsumpun N, Sritularak B, Likhitwitayawuid K (2017) New biflavonoids with a-glucosidase and pancreatic lipase inhibitory activities fromBoesenbergia rotunda. Molecules. https://doi. org/10.3390/molecules22111862

3. Grzelczyk J, Budryn G, Pérez-Sánchez H (2020) Evaluation of affinity of bioactive isolates from various coffee extracts through binding with PPAR- $\gamma$ with the use of isothermal titration calorimetry and docking simulation to prevent antidiabetic effects. $J$ Therm Anal Calorim. https://doi.org/10.1007/s10973-020-09801 $-\mathrm{w}$

4. Jhong $\mathrm{CH}$, Riyaphan J, Lin SH, Chia YC, Weng C (2015) Screening alpha-glucosidase and alpha-amylase inhibitors from natural compounds by molecular docking in silico. BioFactors (Oxford, England). https://doi.org/10.1002/biof.1219

5. Rasouli H, Khodarahmi R, Hosseini Ghazvini SMB, Adibi H (2017) Differential a-amylase/a-glucosidase inhibitory activities of plant-derived phenolic compounds: a virtual screening perspective for the treatment of obesity and diabetes. Food Funct. https ://doi.org/10.1039/C7FO00220C

6. Jayaraj S, Suresh S, Kadeppagari RK (2013) Amylase inhibitors and their biomedical applications. Starch-Stärke 65(7-8):535542. https://doi.org/10.1002/star.201200194

7. Alqahtani AS, Hidayathulla S, Rehman MT (2019) Alpha-amylase and alpha-glucosidase enzyme inhibition and antioxidant potential of 3-oxolupenal and katononic acid isolated fromNuxia oppositifolia. Biomolecules. https://doi.org/10.3390/ biom 10010061

8. Dhital S, Lin A, Hamaker BR, Gidley MJ, Muniandy A (2013) Mammalian mucosal alpha-glucosidases coordinate with alpha-amylase in the initial starch hydrolysis stage to have a role in starch digestion beyond glucogenesis. PLoS ONE 8(4):e62546

9. Nyambe-Silavwe $H$, Villa-Rodriguez JA, Ifie I, Holmes $M$, Aydin $E$, Jensen JM, Williamson G (2015) Inhibition of human a-amylase by dietary polyphenols. J Funct Foods 19:723-732. https://doi. org/10.1016/j.jff.2015.10.003

10. Ugochukwu NH, Babady NE, Cobourne M, Gasset SR (2003) The effect of Gongronema latifolium extracts on serum lipid profile 
and oxidative stress in hepatocytes of diabetic rats. J Biosci 28(1):1-5

11. Agbo C, Baiyeri P, Obi IU (2006) Indigenous knowledge and utilization of Gongronema latifolia Benth.: a case study of women in university of Nigeria, Nsukka. Bio-Research. https://doi. org/10.4314/br.v3i2.28596

12. Johnkennedy N, Adamma E (2011) The protective role of Gongronema latifolium in acetaminophen induced hepatic toxicity in Wistar rats. Asian Pacific J Trop Biomed. https://doi. org/10.1016/S2221-1691(11)60145-7

13. Morebise OA, Fafunso M, Modupe MJ, Olajide O, Awe E (2002) Antiinflammatory property of the leaves of Gongronema latifolium. Phytother Res PTR 16(Suppl 1):S75-S77. https://doi. org/10.1002/ptr.784

14. Owu DU, Nwokocha CR, Obembe AO, Essien AD, Ikpi DE, Osim EE (2012) Effect of Gongronema latifolium ethanol leaf extract on gastric acid secretion and cytoprotection in streptozotocininduced diabetic rats. West Indian Med J 61(9):853-860. https ://doi.org/10.7727/wimj.2011.040

15. Ojo OA, Okesola MA, Ekakitie LI, Ajiboye BO, Oyinloye BE, Agboinghale PE, Onikanni AS (2020) Gongronema latifolium Benth. leaf extract attenuates diabetes-induced neuropathy via inhibition of cognitive, oxidative stress and inflammatory response. J Sci Food Agric 100:4504-4511. https://doi.org/10.1002/ jsfa.10491

16. Akpaso M (2011) Effect of combined leaf extracts of Vernonia amygdalina (bitter leaf) and Gongronema latifolium (Utazi) on the pancreatic $\beta$-Cells of streptozotocin-induced diabetic rats. Br J Med Med Res 1:24-34. https://doi.org/10.9734/BJMMR /2011/215

17. Al-Hindi B, Yusoff NA, Ahmad M, Atangwho IJ, Asmawi MZ, AlMansoub MA, Tabana YM, Bello I, Yam MF (2019) Safety assessment of the ethanolic extract of Gongronema latifolium Benth. leaves: a 90-day oral toxicity study in Sprague Dawley rats. BMC Complement Altern Med. https://doi.org/10.1186/s1290 6-019-2573-x

18. Akah P, Samuel U, Okolo CE (2011) Antidiabetic activity of aqueous and methanol extract and fractions of Gongronema latifolium (asclepidaceae) leaves in alloxan diabetic rats. J Appl Pharm Sci 1:99-102

19. Chime SA, Onyishi IV, Ugwoke PU, Attama AA (2014) Evaluation of the properties of Gongronema latifolium in phospholipon $90 \mathrm{H}$ based solid lipid microparticles (SLMs): an antidiabetic study. J Diet Suppl 11(1):7-18. https://doi.org/10.3109/19390 211.2013.859212

20. Al-Hindi B, Yusoff NA, Atangwho IJ, Ahmad M, Asmawi MZ, Yam MF (2016) A soxhlet extract of Gongronema latifolium retains moderate blood glucose lowering effect and produces structural recovery in the pancreas of STZ-induced diabetic rats. Med Sci (Basel, Switzerland) 4(2):9. https://doi.org/10.3390/medsc i4020009

21. Gabriel El, Uneojo OV, Chukwudi E (2014) Evaluation of methanol extract of Gongronema latifolium leaves singly and in combination with glibenclamide for anti-hyperglycemic effects in alloxan-induced hyperglycemic rats. J Intercul Ethnopharm 3(3):119-122. https://doi.org/10.5455/jice.20140610054950

22. Udoh FV, Eshiet GA, Akpan JO, Edu FE (2013) Hypoglycemic effect of Gongronema latifolia extracts in rats. J Nat Sci Res 3(5):37-44

23. Abdel-sattar E, El-Maraghy S, Dine R, Rizk S (2016) Russelioside $B$, a pregnane glycoside ameliorates hyperglycemia in diabetic streptozotocin induced diabetic rats by regulating key enzymes of glucose metabolism. Chem Biol Interact. https:// doi.org/10.1016/j.cbi.2016.03.033

24. Abdel-Sattar E, Mehanna ET, El-Ghaiesh SH, Mohammad HMF, Elgendy HA, Zaitone SA (2018) Pharmacological action of a pregnane glycoside, russelioside $b$, in dietary obese rats: impact on weight gain and energy expenditure. Front Pharm. https://doi.org/10.3389/fphar.2018.00990

25. Elsayed A, Abdel-sattar E, Khalil M (2020) New calogenin pregnane glycoside derivative from Huernia saudi-arabica and its lipase and a-glucosidase inhibitory activities. Biomed Pharmacother 127:110143. https://doi.org/10.1016/j.bioph a.2020.110143

26. Edet EE, Akpanabiatu MI, Eno AE, Umoh IB, Itam EH (2009) Effect of Gongronema latifolium crude leaf extract on some cardiac enzymes of alloxan-induced diabetic rats. Afr J Biochem Res 3:366-369

27. Gyebi GA, Adebayo JO, Olorundare OE, Pardede A, Ninomiya M, Saheed AO, Babatunde AS, Koketsu M (2018) Iloneoside: a cytotoxic ditigloylated pregnane glycoside from the leaves of Gongronema latifolium Benth. Nat Prod Res 32(24):2882-2886. https://doi.org/10.1080/14786419.2017.1385019

28. Al-Hindi B, Yusoff NA (2019) Safety assessment of the ethanolic extract of Gongronema latifolium benth leaves: a 90-day oral toxicity study in sprague dawley rats. BMC Comp Altern Med. https://doi.org/10.1186/s12906-019-2573-x

29. Sales PM, Souza PM, Simeoni LA, Silveira D (2012) alphaAmylase inhibitors: a review of raw material and isolated compounds from plant source. J Pharm Pharm Sci 15(1):141-183

30. Saini P, Sharma A, Tuli HS, Kashyap D, Kumar Mishra N, Debnath $\mathrm{P}$ (2016) In silico comparative analysis of natural metabolites to alpha glucosidase inhibitors. J Biol Chem Sci 3:226-232

31. Saini P, Debnath P, Tuli HS, Kashyap D (2017) Recent advances in molecular docking studies using a-glucosidase inhibitors. J Biol Chem Sci 4(1):304-308. https://doi.org/10.22159/ijpps .2017v9i6.14389

32. Saleem M, Yu SM, Rafiq M, Kim SJ, Seo SY, Lee KH (2014) Synthesis, crystal structure, anti-inflammatory and anti-hyperglycemic activities of novel 3,4-disubstituted 1,2,4-triazol-5(4H)one derivatives. Med Chem 10(8):810-823

33. Kim YM, Jeong YK, Wang MH, Lee WY, Rhee HI (2005) Inhibitory effect of pine extract on alpha-glucosidase activity and postprandial hyperglycemia. Nutrition 21(6):756-761. https ://doi.org/10.1016/j.nut.2004.10.014

34. Honda M, Hara Y (1993) Inhibition of rat small intestinal sucrase and a-glucosidase activities by tea polyphenols. Biosci Biotechnol Biochem 57(1):123-124. https://doi.org/10.1271/ bbb. 57.123

35. Gyebi GA, Ocheje JO, Ogunyemi OM (2019) Molecular docking studies on bioactive compounds from clove ( Syzygium Aromaticum) on metabolic regulators in cancer Salem university. J Life Sci 1(1):1-18

36. Trott O, Olson AJ (2010) Autodock vina: improving the speed and accuracy of docking with a new scoring function, efficient optimization, and multithreading. J Comput Chem 31(2):455461. https://doi.org/10.1002/jcc.21334

37. Sanchez-Linares I, Perez-Sanchez H, Cecilia JM, Garcia JM (2012) High-throughput parallel blind virtual screening using BINDSURF. BMC Bioinform 13(Suppl 14):S13. https://doi. org/10.1186/1471-2105-13-s14-s13

38. Eleyinmi AF (2007) Chemical composition and antibacterial activity of Gongronema latifolium. J Zhejiang Univ Sci B 8(5):352-358. https://doi.org/10.1631/jzus.2007.B0352

39. Nwanna EE, Oyeleye SI, Ogunsuyi OB, Oboh G, Boligon AA, Athayde ML (2016) In vitro neuroprotective properties of some commonly consumed green leafy vegetables in Southern Nigeria. NFS J 2:19-24. https://doi.org/10.1016/j.nfs.2015.12.002

40. Balogun $M$, Besong E, Obimma J, Mbamalu O, Djobissie S (2016) Gongronema Latifolium: A Phytochemical, Nutritional and Pharmacological Review. J Physiol Pharmacol Adv 6:1. https://doi. org/10.5455/jppa.1969123104000 
41. Liu S, Chen Z, Wu J, Wang L, Wang H, Zhao W (2013) Appetite suppressing pregnane glycosides from the roots of Cynanchum auriculatum. Phytochemistry 93:144-153. https://doi. org/10.1016/j.phytochem.2013.03.010

42. Kiem PV, Yen DTH, Hung NV, Nhiem NX, Tai BH, Trang DT, Yen $\mathrm{PH}$, Ngoc TM, Minh CV, Park S, Lee JH, Kim SY, Kim SH (2020) Five new pregnane glycosides from gymnema sylvestre and their a-glucosidase and a-amylase inhibitory activities. Molecules 25(11):2525. https://doi.org/10.3390/molecules25112525

43. Srisurichan S, Pornpakakul PS, S, (2014) Pregnane-type steroidal glycosides from Gymnema griffithii Craib. Phytochemistry. https ://doi.org/10.1016/j.phytochem.2014.06.014

44. Moorthy NS, Ramos MJ, Fernandes PA (2012) Studies on alphaglucosidase inhibitors development: magic molecules for the treatment of carbohydrate mediated diseases. Mini Rev Med Chem 12(8):713-720. https://doi.org/10.2174/1389557128 01264837

45. Rouzbehan S, Moein S, Homaei A, Moein MR (2017) Kinetics of alpha-glucosidase inhibition by different fractions of three species of Labiatae extracts: a new diabetes treatment model. Pharm Biol 55(1):1483-1488. https://doi.org/10.1080/13880 209.2017.1306569

46. Nahoum $V$, Roux $G$, Anton $V$, Rougé $P$, Puigserver $A$, Bischoff $H$, Henrissat B, Payan F (2000) Crystal structures of human pancreatic alpha-amylase in complex with carbohydrate and proteinaceous inhibitors. Biochem J 346:201-208

47. Rydberg EH, Li C, Maurus R, Overall CM, Brayer GD, Withers SG (2002) Mechanistic analyses of catalysis in human pancreatic alpha-amylase: detailed kinetic and structural studies of mutants of three conserved carboxylic acids. Biochemistry 41(13):4492-4502. https://doi.org/10.1021/bi011821z

48. Williams LK, Li C, Withers SG, Brayer GD (2012) Order and disorder: differential structural impacts of myricetin and ethyl caffeate on human amylase, an antidiabetic target. J Med Chem 55(22):10177-10186. https://doi.org/10.1021/jm301273u

49. Roig-Zamboni V, Cobucci-Ponzano B, lacono R, Ferrara MC, Germany S, Bourne Y, Parenti G, Moracci M, Sulzenbacher G (2017) Structure of human lysosomal acid a-glucosidase-a guide for the treatment of Pompe disease. Nat Commun 8(1):1111. https ://doi.org/10.1038/s41467-017-01263-3

Publisher's Note Springer Nature remains neutral with regard to jurisdictional claims in published maps and institutional affiliations. 